UDC 615.361.11/13-089.014.41:612.014.482.31

Manchenko A. A., Mikhailova I. P., Sandomirsky B. P.

Institute for Problems of Cryobiology and Cryomedicine NAS of Ukraine, Kharkiv, Ukraine

e-mail: anna.gorlenko@gmail.com

\title{
MORPHOLOGY OF TISSUE REACTION IN RATS AFTER SUBCUTANEOUS IMPLANTATION OF PORCINE PERICARDIUM AND AORTIC VALVE LEAFLETS DEVITALIZED BY CRYORADIATION
}

\section{ABSTRACT}

The decrease of immunogenicity is a priority requirement to pre-implantation treatment of the xenogeneic graft tissue. To create tissue implants of the pericardium and aortic valve leaflets, we have developed a method of devitalizing treatment, based on the combined effect of low temperatures $\left(-196^{\circ} \mathrm{C}\right)$ and ionizing $\beta$-radiation. This approach provides deletion to the main targets of biomaterial immunogenicity due to the effects of successive cryo- and radiation damage, as well as the activation of radiation-induced apoptosis.

The purpose of research was to assess the impact of low-temperature and radiation and their synergistic effect on the biocompatibility of devitalized xenogeneic tissues.

METHODS. Histological tests were used to study tissue reaction in experimental animals after implantation of native porcine pericardium and aortic valve leaflets (control), grafts after freezing-thawing and grafts after freezing-thawing with irradiation at a dose of $25 \mathrm{kGy}$. After 7,14 days and 1, 3, 6 and 12 months we evaluated the morphological changes of implant structure, inflammatory response of the recipient's tissue, formation of the capsule and its degree of maturity, the xenogeneic cells survival and recovery of recipient's surrounding tissue.

RESULTS. Comparative analysis has revealed fundamental differences of engraftment indicators and tissue reaction of cryopreserved and irradiated samples from implants after freezing and $\beta$-radiation. Cryoradiation processing greatly reduced the immune response to the implantation. Devitalized tissues promoted early stimulation of recipient's tissues repair, maintained compactness and structural integrity. After a year the border between the implant and connective tissue erased, biomaterial was fully sprouted with recipient's tissue. The observed changes testify to the integration of implant's connective tissue, followed by its replacement.

CONCLUSION. Our study has confirmed the possibility of using xenogeneic pericardium and aortic valve leaflets, being modified by cryoradiation method to restore soft tissue structures.

KEYWORDS: tissue implants, pericardium, aortic valve, tissue devitalization, cryopreservation, ionizing radiation

Devitalization of the original animals tissue is one of the ways for creating xenogeneic tissue implants used in reconstructive and restorative surgery to improve repair processes and renew the structural and functional elements in the damaged tissues and organs. Devitalizing treatment is intended to solve the following tasks: (1) to prevent immunological conflict by removing or destroying donor cells in the implanted tissue (devitalization), that significantly reduces the recipient's immune response; (2) to stabilize the tissue structure (preservation); (3) to maintain adequate biomechanical properties; and (4) to observe sterility of implants. Following transplantation, the acellular xenogeneic graft will be gradually populated with autologous cells to form a stable structure of biological prosthesis. The connective fibers will be slowly lysed by macrophages and a xenograft will fully integrate into the recipient's tissue. 
Most methods of obtaining tissue bioimplants from xenogeneic tissues are based on the on-going processing by various enzymes and preserving solutions (various concentrations of glutaraldehyde and epoxy compounds of different compositions), a variety of hypo- and hypertensive buffers the action of which is associated with destruction of the immunogenic proteins, tissue tanning and structural stabilization. Chemical treatment methods can effectively reduce antigenic properties of tissues and prevent their bacterial contamination due to the antiseptic effects. At the same time, these methods have a number of disadvantages, such as residual cytotoxicity, greater probability of tissue calcification, as well as damage of structural proteins of the tissue matrix [1-3].The above-listed effects greatly limit the application of such methods in clinical practice.

To obtain tissue implants from porcine pericardium and aortic valve leaflets (AVL) we have developed a method of devitalizing processing, based on the combined effect of low temperatures $\left(-196^{\circ} \mathrm{C}\right)$ and ionizing $\beta$-radiation. This method was first tested by us to create small-diameter vascular prostheses from pig arteries [4]. This approach provides damage of the main targets of the biomaterial immunogenicity due to the effects of successive cryo- and radiation damage, as well as radiationinduced apoptosis activation. This method excludes the use of chemical reagents, thereby increasing the quality of tissue implants and reducing a risk of complications after transplantation; and provides a complete viral and bacterial sterilization of the biomaterial. Low temperatures solve the problem of biological material preservation at intermediate stages of the technological process and long-term storage of tissue equivalents.

In our previous works, we studied morphology, structural, antigenic characteristics and strength-elastic properties of xenogeneic tissues under the influence of low temperatures, ionizing radiation and their combined effects. Cryoradiation treatment caused degradation and loss of surface pavement (endothelium, mesothelium) and expressed destructive changes of all cellular elements in the pericardium and AVL, while keeping the spatial arrangement and interconnections, as well as the struc- tural integrity of fibrous components of connective tissue framework. The expression of a-Gal epitope, the main xenoantigen, decreases 3-fold in the treated pericardium and leaflets in the comparison with native tissue, thus reducing the immunogenic potential of the tissue and providing biocompatibility of implants at xenogeneic prosthetics. The devitalized tissues possess/adequate physical and mechanical properties characteristic of native tissues in both longitudinal and transverse directions. Deep freezing and $\beta$-radiation initiate formation of additional cross-linking and exhibit synergistic effects: increased strength and elastic properties, providing for structural stabilization and preservation of the implant [5-7].

The processes occurring in recipient's tissues after xenogeneic tissue implantation in experimental biological models are of great importance for studying biomaterials biocompatibility. Reaction to the implantation is the main criterion of material ability to be integrated into patient's organism and induce cellular or tissue response needed for achieving optimal therapeutic effect. It is believed that devitalized biomaterials, containing only fibrous elements, have low antigenicity. The collagen and elastic fibers, making up xenogeneic transplants, have species specificity, conditioning basically different reaction of the recipient organism.

Thus, during implantation of allogeneic tissues the immune response is limited solely by the macrophage activity, whereas the decay products provide phenotypic maturation of various macrophages populations. Therefore, the implantation of allogeneic biomaterials leads to the formation of adequate regenerate. Xenogeneic biomaterial causes typical reaction of cell-mediated immunity, evidently, due to the macrophages functional failure leading to chronic course of inflammation and formation of connective cicatricial tissue in the implantation zone [8]. The morphological processes, occurring in the recipient's tissues after implantation of xenogeneic pericardium and aortic valve leaflets modified by cryoradiation method have not been studied so far.

The purpose of our study was (a) to follow the dynamic of tissue reaction in the response to implantation of xenogeneic pericardium and
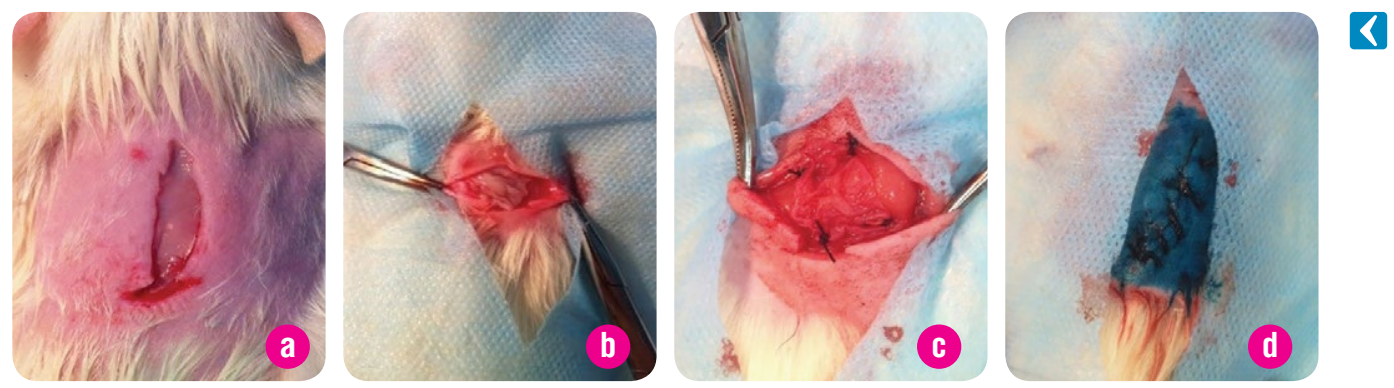

Fig. 1. Surgery procedure of tissue grafts implantation:

a) skin incision up to $2 \mathrm{~cm}$;

b) subcutaneous implantation

of tissue grafts:

c) fixation using suture

in 4 points;

d) wound closure.
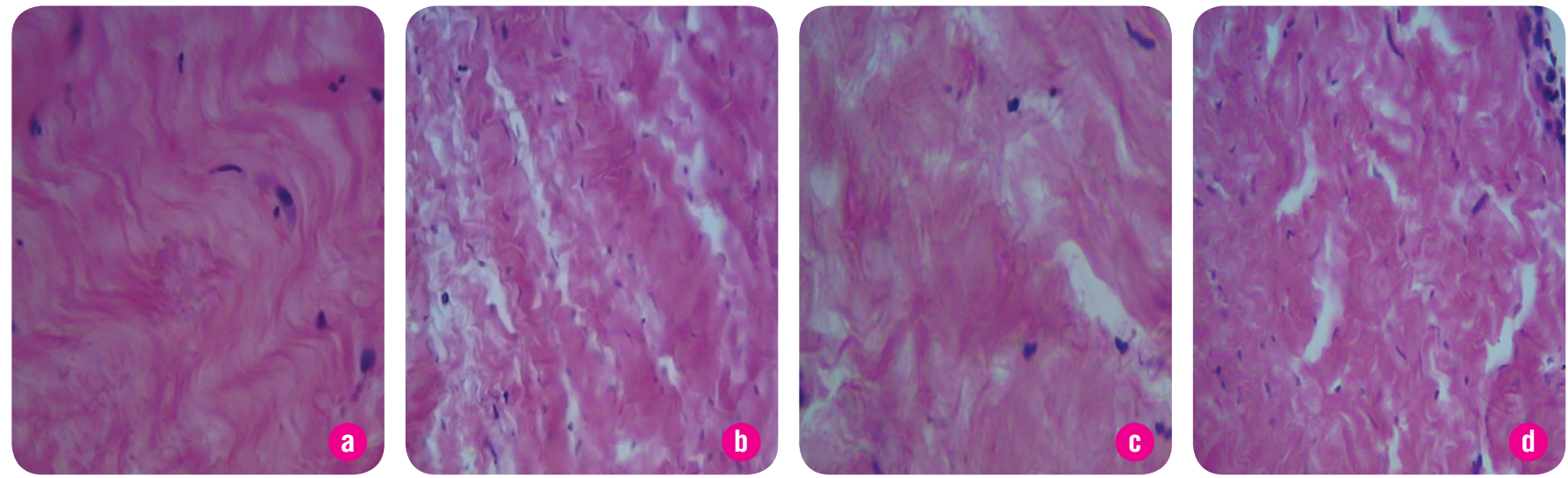

Fig. 2. The micrographs fragment of the pericardium, 7 days after implantation. Hematoxylin and eosin staining, oc. x40, ob. x10.

a) the native pericardium (group N) with normal fibroblasts;

b) group F - thin deformed fibroblast nuclei, with preserved structure of fiber bundles and cavities between the bundles;

c) group $\mathrm{R}$ - dead fibroblasts, stroma unfolding with the loss of tortuosity;

d) group FR - dead fibroblasts, the fibers with the preserved structure and small microfissure between the bundles. 
aortic valve leaflets after low-temperature and radiation impacts in the rats, as well as the specifics of their resorption and biointegration; and (b) to assess the synergistic effect of cryoradiation on the biocompatibility of devitalized xenogeneic tissues.

\section{MATERIALS AND METHODS}

Pericardium and AVL of 6 -8-month-old outbred pigs were used in the study. Tissues were isolated within 5 minutes after the euthanasia of animal in aseptic condition. Within one hour, they were transported to the laboratory, dissected and washed with cold sterile $0.9 \% \mathrm{NaCl}$ solution with antibiotic Bicillin-3 (Kyivmedpreparat, Ukraine).

Pericardial tissue and AVL were divided into 4 groups for different cryoradiation treatment: No. $1(\mathrm{~N})$ - native tissues; No. $2(\mathrm{R})$ - the tissues irradiated at a dose of $25 \mathrm{kGy}$; No. $3(\mathrm{~F})$ - the tissues after freezing $\left(-196{ }^{\circ} \mathrm{C}\right)$ and thawing; No. 4 (FR) - tissues after freezing-thawing, and subsequent irradiation at a dose of $25 \mathrm{kGy}$. Samples in cryovials (Deltalab, Spain) were transferred in liquid nitrogen at a rate of freezing $40^{\circ} \mathrm{C} / \mathrm{sec}$. Thawing of containers was performed in a water bath at $+36^{\circ} \mathrm{C}$. The samples were irradiated with an electron flow using a linear particle accelerator «LUE-10» (Ukraine). After irradiation, sterile containers with samples were stored in liquid nitrogen vapor at a temperature from -150 to -170 ${ }^{\circ} \mathrm{C}$. Native tissue samples were implanted 10-12 hours after obtaining.

Animal experiments were carried out on the basis of the vivarium of the Institute for Problems of Cryobiology and Cryomedicine in aseptic condition, in accordance with the «General Principles of animal experiments», approved by the 3rd National Congress on Bioethics (Kyiv, 2007) and consistent with the position of «European Convention on protection of vertebrate animals used for experimental and other scientific purposes» (Strasbourg, 1986).

Implantation of samples in experimental animals was performed under the skin in interscapular region according to the method of Fishbein M. et al (1982). This region is characterized by low mobility and availability to the animal that minimizes interference in the experimental process. The experiment was performed on the 5-6-month-old male Wistar rats 200-250 g in weight. Hair was removed from the surgical field, and the skin was treated with $70 \%$ ethanol. The operation was performed under sterile conditions under ether anesthesia. On rat back, $2 \mathrm{~cm}$ skin incision was made and subcutaneous pockets were formed (Fig. 1). The prepared $1 \times 1 \mathrm{~cm}$ implants were placed into the pocket and fixed at the corners to the muscle tissue with single suture Vicryl (Ethicon, USA). The incision was closed with nonabsorbable suture. After surgical procedure, all animals kept the physiological activity. The animals were euthanized on the $7^{\text {th }}, 14^{\text {th }}$ day and $1,3,6$ and 12 months after surgery by decapitation under ether anesthesia. These terms were chosen, with an account being taken of the developing reparative processes and high-grade scar formation [9].

Tissue response and change of biomaterial structure after implantation was studied by light microscopy. Tissue complex of rat's scapular region, including implanted structure, served the material for histological study. Samples for morphological study were dissected with the surrounding and underlying tissue. Fixed in $10 \%$ neutral formalin, the tissue fragments were passing through a series of increasing alcohol concentrations and embedded in celloidin-paraffin. Sections of 6-7 microns thick were stained with hematoxylin and eosin. Light microscopy was performed on a microscope Magnum TPL (Medline Scientific Limited, UK), microphotography with camera Sigeta (South Korea), photomicrographs processing with the help of image processing software for digital cameras Sigeta.

As a marker of successful engraftment or biodestruction of the graft, we used the following morphological parameters: changes in the structure; intensity and duration of the inflammatory response from the recipient's tissues; time of formation of the capsule and the degree of its maturity; cell survival; and the rate of recovery of the original structure of recipient's bed tissues. It is very important whether a graft maintains structural integrity or undergoes fragmentation and resorption. These factors determine the speed of vascularization and change of cell associations from polymorphous cells to lymphocytes or macrophages, and later on the fibroblast type. This determines the time and rate of formation of collagen fiber capsule which is the barrier and the link between graft and recipient tissues $[8,10]$. To obtain more objective data we performed semi-quantitative assessment of the inflammatory response: 0 - no evidence; $(+)$ - single cells (neutrophils, lymphocytes, macrophages, eosinophils); (++) - small foci; $(+++)$ - single and confluent foci; $(++++)$ - extensive infiltrates.

\section{RESULTS AND DISCUSSION}

On the $7^{\text {th }}$ day, in all the animals with implanted samples of the pericardium and AVL the early tissue changes had qualitatively similar pattern and all signs of acute traumatic inflammation: neutrophilic infiltration, edema, cysts with detritus, macrophage reaction, proliferation of fibroblastic cells, capillary formation and sprouting of granulation tissue into the implant. At this stage, a thick border of granulation tissue surrounded all samples. In a series of experiments on replanting the AVL, unlike pericardium, no inflammatory changes of the adipose tissue were observed. Qualitative differences concerned the condition of the implant. Native implants were represented by the unfolded fibrous tissue in which a tortuosity of fibers retained with well detected numerous fibroblasts (Fig. 2, a).

The cellular infiltrate began merging engrafted sample invading it to grow between its structures. After freezing-thawing (Group F) the fibers in the implant were arranged compactly, their structural integrity maintained, cavities appeared between the fiber bundles. Numerous weakly stained fibroblast nuclei were deformed (Fig. 2, b). In the implants subjected to $\beta$-radiation (group R), we observed the unfolding of collagen fiber bundles, reduction or loss of their tortuosity. The fibroblasts had pyknotic nuclei or unusually elongated form testifying to their death. (Fig.2, c). After cryoradiation treatment the implants (group FR) contained well-defined fiber bundles without separation of fibers, thinning and reducing of tortuosity in them. The implant was more compact in its center than at the periphery and contained few fibroblast nuclei with karyorrhexis features (Fig. 2, d).

\section{IMPLANTATION OF NATIVE SAMIPLES OF PERICARDIUM \\ AND THE AVL (GROUP N)}

By the $14^{\text {th }}$ day of replanting native specimens, the severity of inflammatory response diminished and the period of proliferation followed with formation of vascular network. We observed the fragmentation of xenogeneic implants with edema of fibers surrounded by a thick border of lymphocytes, macrophages and granulation tissue. There occurred a marginal destruction of the fragments not soldered with recipient's tissues (Fig. 3, a). That is, rejection ensued after traumatic reaction fading. One month after implanting, the implants were fragmented and consisted of the unfolded and swollen fibers. In the destruction area, there were cysts with lysed tissue; the granulation tissue remained on the periphery, and there was a border of round cells between them (Figure 3, b.).

By the 3rd month small pieces of implants remained in the implantation zone. They were surrounded by a capsule along the perimeter, the internal thin layer of which was represented by the cellular infiltrate with prevailing lymphocytes, macrophages, plasma cells, eosinophils and fibroblasts. The same cells densely infiltrated the implant itself. Outside this thin cell layer, the implant was surrounded with the layer of pigmented macrophages (Fig. 3, c). In the tissue between the fragments, the large number of giant multinucleated cells involved in graft resorption was detected (Fig. 3, d).

After 6 months, there was a complete resorption of the implant (Fig. 3, e). A year later the implanted samples were virtually absent being represented only by very small fragments (Fig. 3, f). 

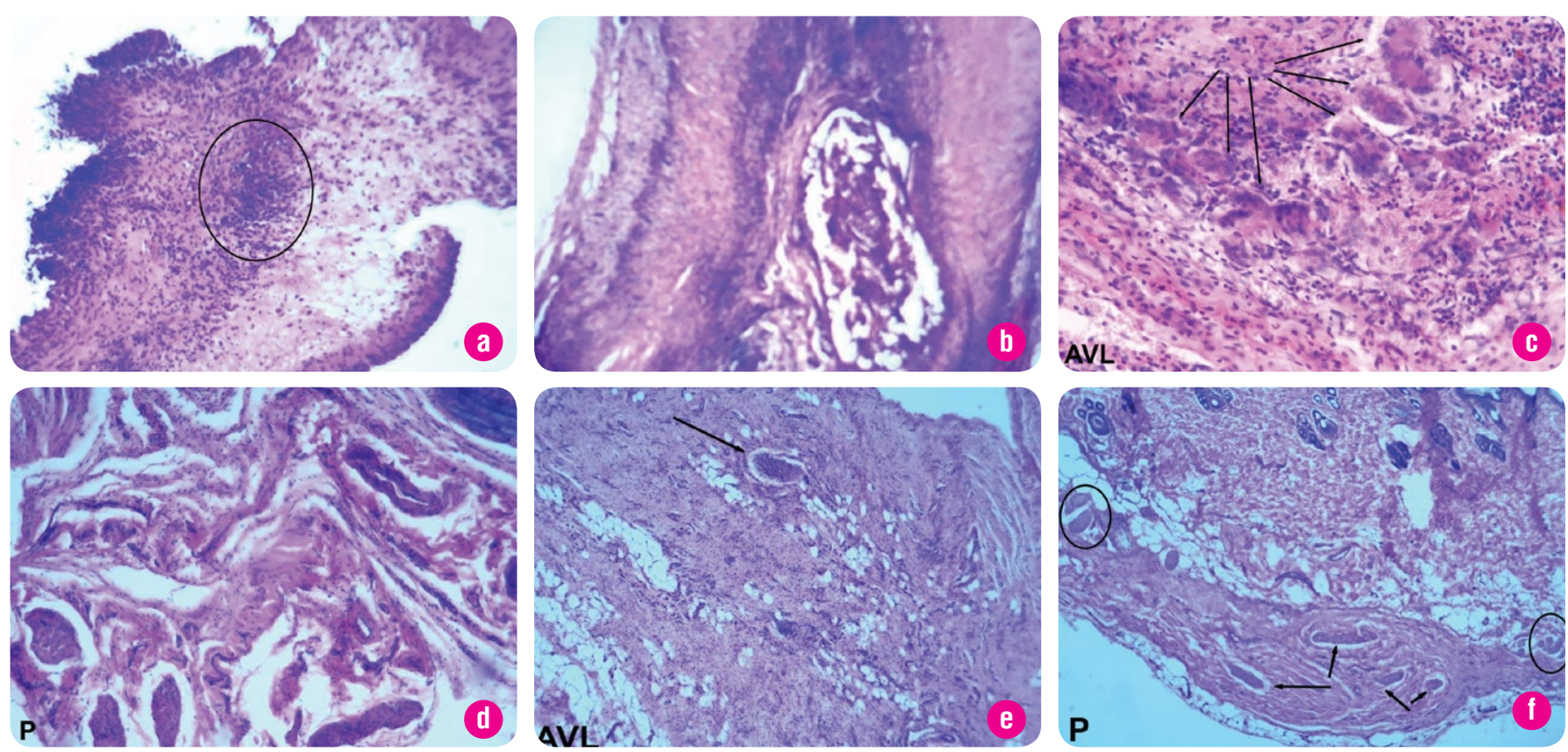

A Fig. 3. Photomicrographs of aortic valve leaflets (AVL), pericardium (P) and the morphology of surrounding tissues after implantation; Group N (native tissues) Hematoxylin and eosin staining.

a) after 14 days: edge biodegradation of the fragment, neutrophilic infiltration; oc. x10, ob. x10;

b) after 1 month: destruction zone, a cyst with resorption inside of the fragment; oc. x4, ob. x10;

c) after 3 months: multinucleated giant cells outwards the capsule (arrows); oc. $\times 25$, ob. x10;

d) after 3 months: fragments of the implant with lymphoid infiltrates, cysts, degenerative changes in the fibers; oc. x10, ob. x10;

e) after 6 months: subcutaneous adipose tissue with normal structure, the transplant fragment (arrow); oc. x4, ob. x10;

f) after 12 months: small fragments of the implant (arrows) in connective tissue. Edema pattern of muscle fibers (the circle); oc. x4, ob. x10.
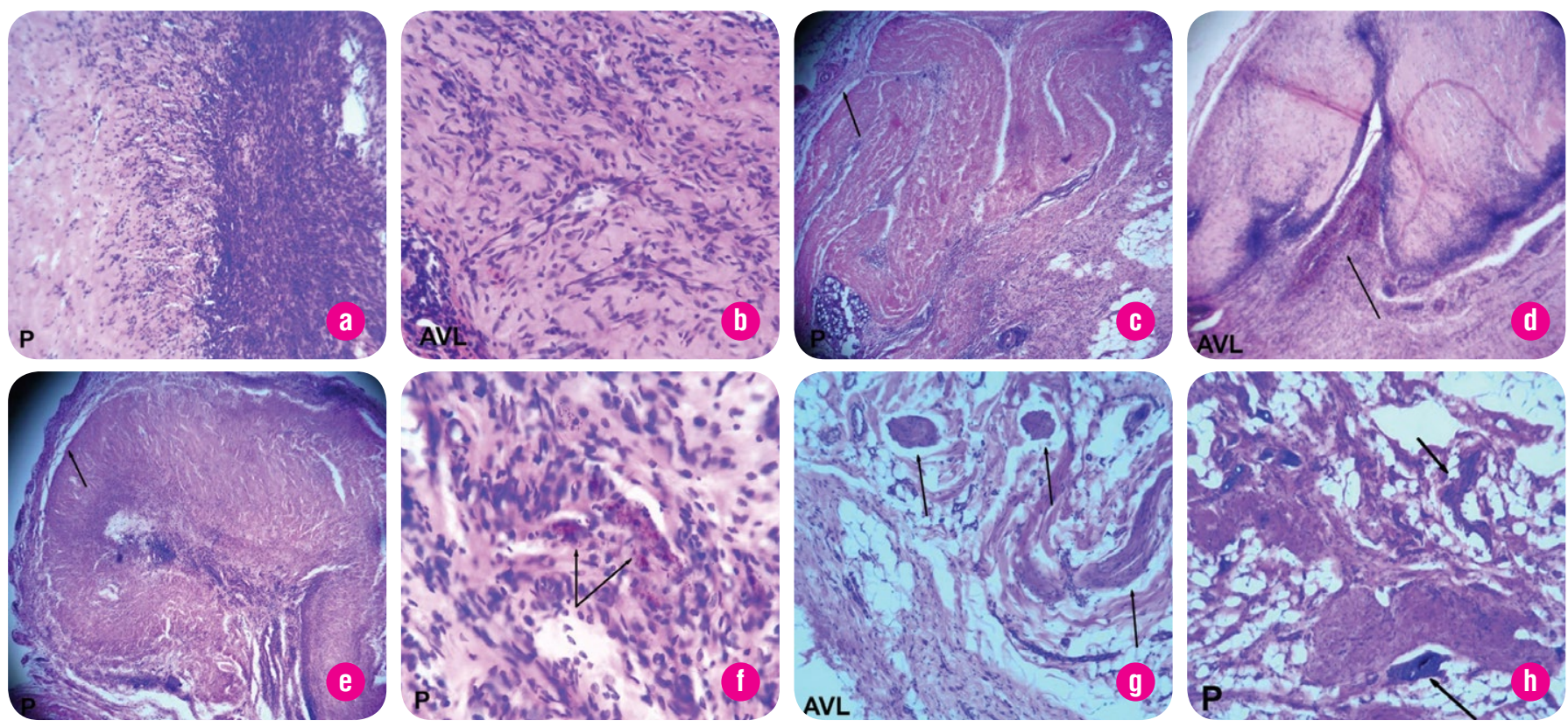

Fig. 4. Photomicrographs of the aortic valve leaflets (AVL), pericardium (P) and the morphology of surrounding tissues after implantation. Group $F$ (tissues irradiated at a dose of $25 \mathrm{kGy})$. Hematoxylin and eosin staining.

a) after 14 days: the inner layer of the capsule - round cells, the outer layer - granulation tissue; oc. x25, ob. x10;

b) after 14 days: invasion of fibroblasts and capillaries; oc. x25, ob. x10;

c) after 1 month: the implant is surrounded by a thin capsule of loose connective tissue (arrow); adipose tissue has a normal structure; oc. x4, ob. x10;

d) after 1 month: a capsule of loose connective tissue, implant with few cells; oc. x25, ob. x10;

e) after 3 months: the implant is compact, surrounded by a thin capsule of fibrous connective tissue (arrow); oc. x4, ob. x10;

f) after 3 months: pigmented macrophages in the surrounding tissue (arrows); oc. $x 40,0 b . x 10$;

g) after 6 months: small and thin ribbon-like implant fragments (arrows); oc. x4, ob. x10;

h) after 12 months: fragments of the transplant, surrounded by the normal subcutaneous adipose tissue, lymphoid infiltration of small fragments (arrows);

oc. $\times 20,0 b . x 10$. 


\section{IMPLANTATION OF FROZEN-THAWED SAMPLES OF PERICARDIUM AND AVL (GROUP F)}

At 14 days post replanting, AVL did not lyse and were presented by very large fragments, almost merging with the surrounding tissue. Pericardium was compact, sometimes edematous; its cellularity was lower than in the previous period. There were cysts with resorbed material at the edges. The implants were surrounded by a thin capsule. Two layers could be distinguished in it: an inner, consisting mainly of a number of connective tissue cells and macrophages, and an outer presented by wellvascularized granulation tissue (Figure 4, a). Capillaries sprouted directly into the implant together with a small amount of fibroblasts, histiocytes and lymphocytes to form an inner zone of the capsule (Fig. 4, b).

One month after implantation the samples, subjected to low temperature impact, were well visualized. The pericardium had a compact structure in the form of a thin strip windings surrounded by a thin capsule of loose connective tissue (LCT) containing more cells than fibers. Lymphocytes, macrophages and fibroblasts dominated among cellular components (Fig. 4, c). A thin border of lymphoid cells surrounded AVL with a mature granulation tissue outwards. Although fibers were edematous in some places, there was a low cellular infiltration in the implant center. The surrounding tissue, which restored its normal structure, had many pigmented macrophages (Fig. 4, d), that is, there was no inflammatory response of the tissue to the implant.

Three months after replanting the implants retained their structure, they were encapsulated by a thin strip of dense connective tissue with minimum inflammatory changes in the surrounding tissue (Fig. 4, e) The area of location of the samples exhibited small accumulations of macrophages, histiocytes and fibroblasts (Fig. 4, f).

A similar morphological pattern was seen in the area of implantation at a period of 6 and 12 months. AVL were defined as numerous small and ribbon-like fragments. They were not encapsulated, arranged separately and surrounded by tissue without inflammation (Fig. 4, g).The pericardium in some animals was represented by large fragments with sites of adipose tissue without inflammation, although in some small fragments there was infiltration with lymphocytes. In some cases, the implant was not detected (Fig. 4, h).

\section{IMPLANTATION OF THE $\beta$-IRRADIATED SAMPLES OF \\ XENOGENEIC PERICARDIUMI AND AVL (GROUP R)}

Since early terms of observation, a severe inflammatory response with neutrophil infiltration was developing in the sites of implant contact with recipient tissues, and there was a destruction of tissue structures. Because of the lysis, AVL were divided into thin ribbons or were absorbed by creeping infiltration (Fig. 5, a). The most of the pericardium remained compact. There were no signs of fragmentation and active resorption (Fig. 5, b).

By the $1^{\text {st }}$ month the inflammatory infiltration in the area of implant location was diminished or completely disappeared. Large transplant fragments were placed separately from surrounding tissues with no signs of lymphocyte and macrophage inflammation around the perimeter. There were clusters of pigmented macrophages with inclusion of single lymphocytes (Fig. 5 c, d).

Within 3 months after implantation, AVL represented relatively large fragments, connected to each other by narrow isthmuses. The graft was
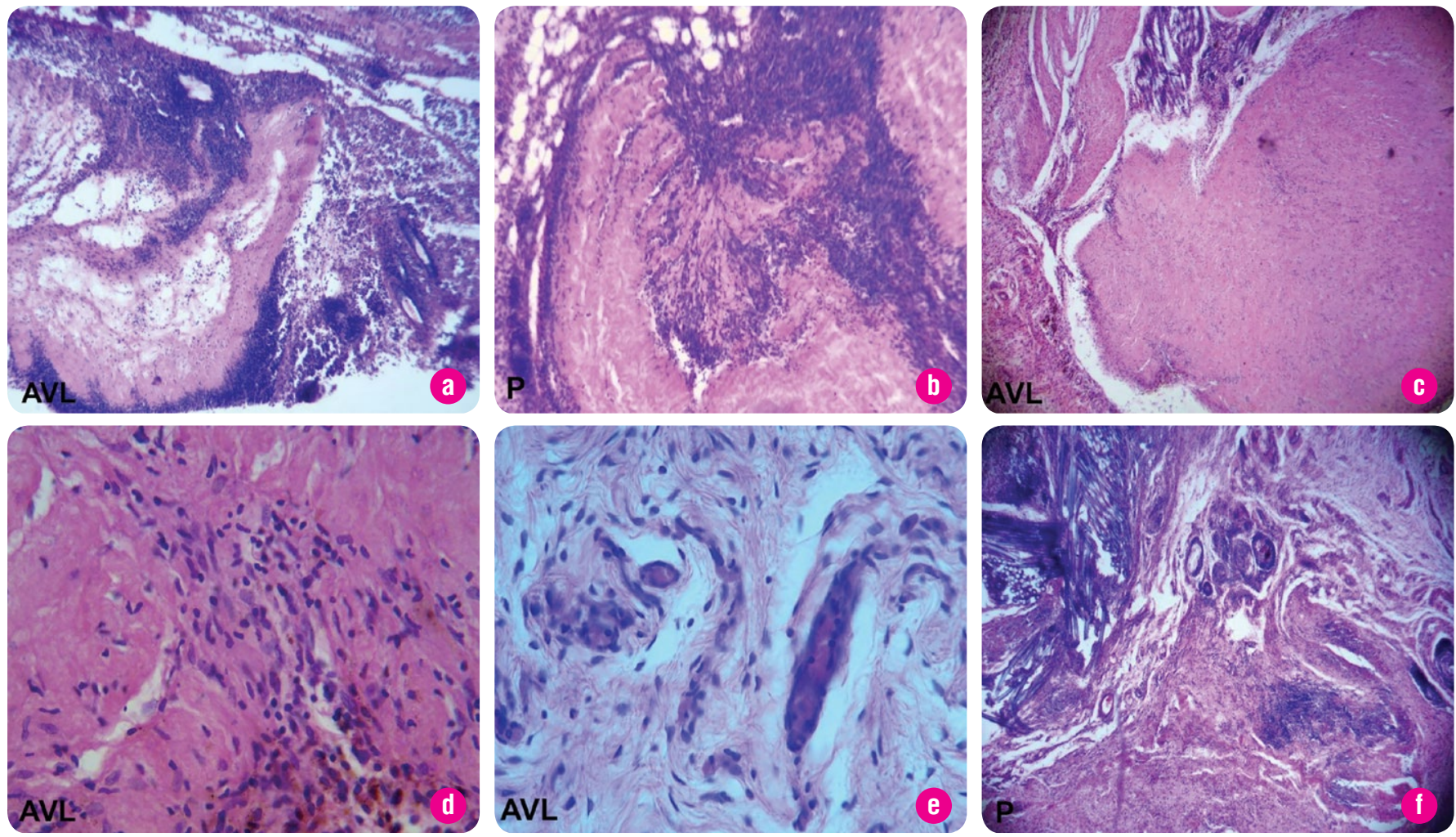

Fig. 5. Photomicrographs of aortic valve leaflets (AVL), pericardium (P) and the morphology of surrounding tissues after implantation. Group R (tissue after freezing and thawing). Hematoxylin and eosin staining.

a) after 7 days: neutrophilic infiltration and resorption of implant fragments; oc. x10, ob. x10

b) after 7 days: cell strands and newly formed capillaries sprouting in the implant; oc. x25, ob. x10;

c) after 1 month: free-ended implant is not surrounded by a capsule, surrounding tissues are without inflammation; oc. x4, ob. x10;

d) after 1 month: a small cluster of lymphocytes and pigmented macrophages; oc. x40, ob. x10;

e) after 3 months: numerous macrophages, fibroblasts, full-blooded vessels; oc. $x 25$, ob. x10;

f) after 3 months: the implant in a loose connective tissue capsule, the surrounding tissue has a normal structure, large cysts with the resorbed fragments are visible; oc. $x 4,0 b . x 10$ 

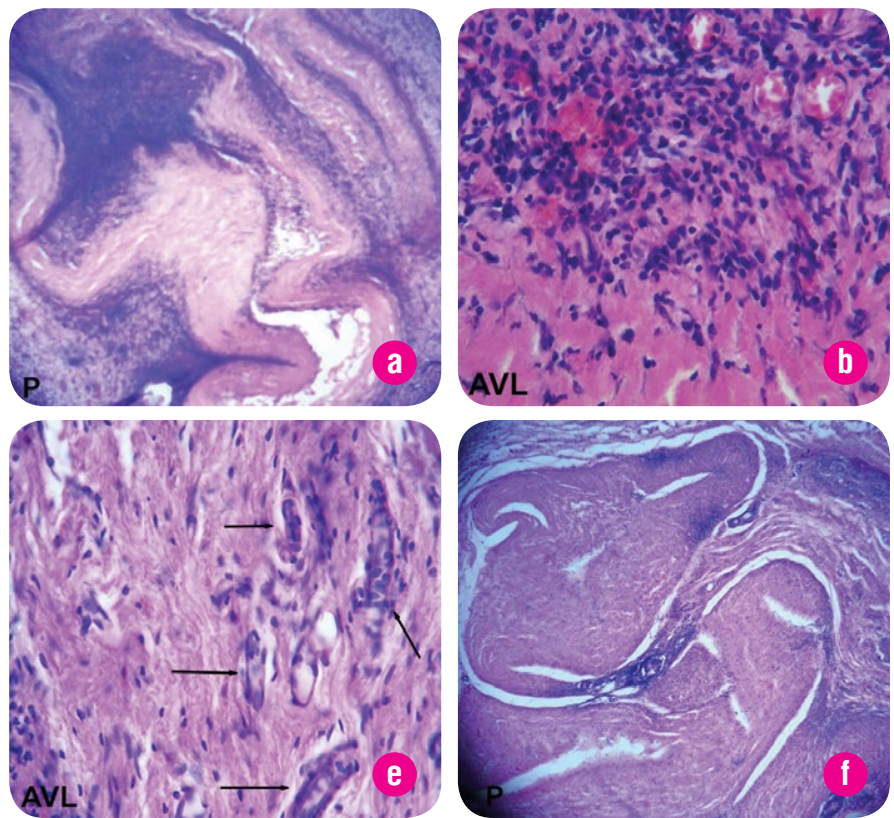

unfolded, more thin and fragmented, in comparison with the original version, contained numerous macrophages and fibroblast nuclei as well as full-blooded microvessels. The capsule was not detected. The pericardium, surrounded by a capsule of the LCT, remained relatively consistent, but large fragments of biomaterial with adjacent cysts were observed outward the capsules. The cysts contained residues of both biomaterial and destroyed tissues of the recipient. The layers of granulation tissue with good vascularization and a plenty of plasma cells, macrophages, lymphocytes and giant cells, which carried out the lysis of the implant, separated cysts and fragments of the implant (Fig. 5, e, f).

\section{IMPLANTATION OF DEVITALIZED (FROZEN AND IRRADIATED)} SAMPLES OF THE PERICARDIUM AND AVL (GROUP FR)

Xenoimplants retained their structure, there was no fragmentation and small focal unfolding was observed in 14 days after implanting. Outside the pericardium was surrounded by a two-layer connective tissue capsule: its outer layer was presented by granulation tissue and its internal layer by connective tissue acquiring a fibrous type (Figure 6, a).

Accumulations of round cells occurred in the contact points between the implant structures. The surrounding tissue contained a lot of fibroblasts, lymphocytes, giant cells and eosinophils. There was an active angiogenesis of AVL in the implantation area: new capillaries appeared from good full-blooded capillaries of the surrounding tissue; proliferation and migration of fibroblast cells continued simultaneously with angiogenesis (Fig. 6, b). We can assume that devitalized samples contributed to the stimulation of an early repair of its own tissues. Vascular response with cell proliferation in the area of xenogeneic tissue implantation is aimed at compensation of lysed structures of donor material.

By the $1^{\text {st }}$ month, most xenoimplants remained compact. Formed capsule of AVL consisted of 2 layers: the external- with sites of loose connective tissue, sometimes fibrous: and inner - represented by a thin border of lymphocytes, which were lined up along the edge of the transplant (Fig. 6, c). A thin capsule surrounding the pericardium represented fibrous connective tissue (FCT) and almost merged with the surrounding tissues without signs of inflammation. By that time, at the site of xenogeneic leaflets implantation, subcutaneous adipose tissue was completely restored and contained macrophages with pigment granules in the cytoplasm and giant multinucleated cells (Fig. 6, d).

By the $3^{\text {rd }}$ month the transplants almost merged with the surrounding tissue, enclosed with the capsule of fine fibrous connective tissue and well vascularized. On the periphery of the sample, cellularity increased due to the presence of fibroblasts in addition to lymphocytes, macro-
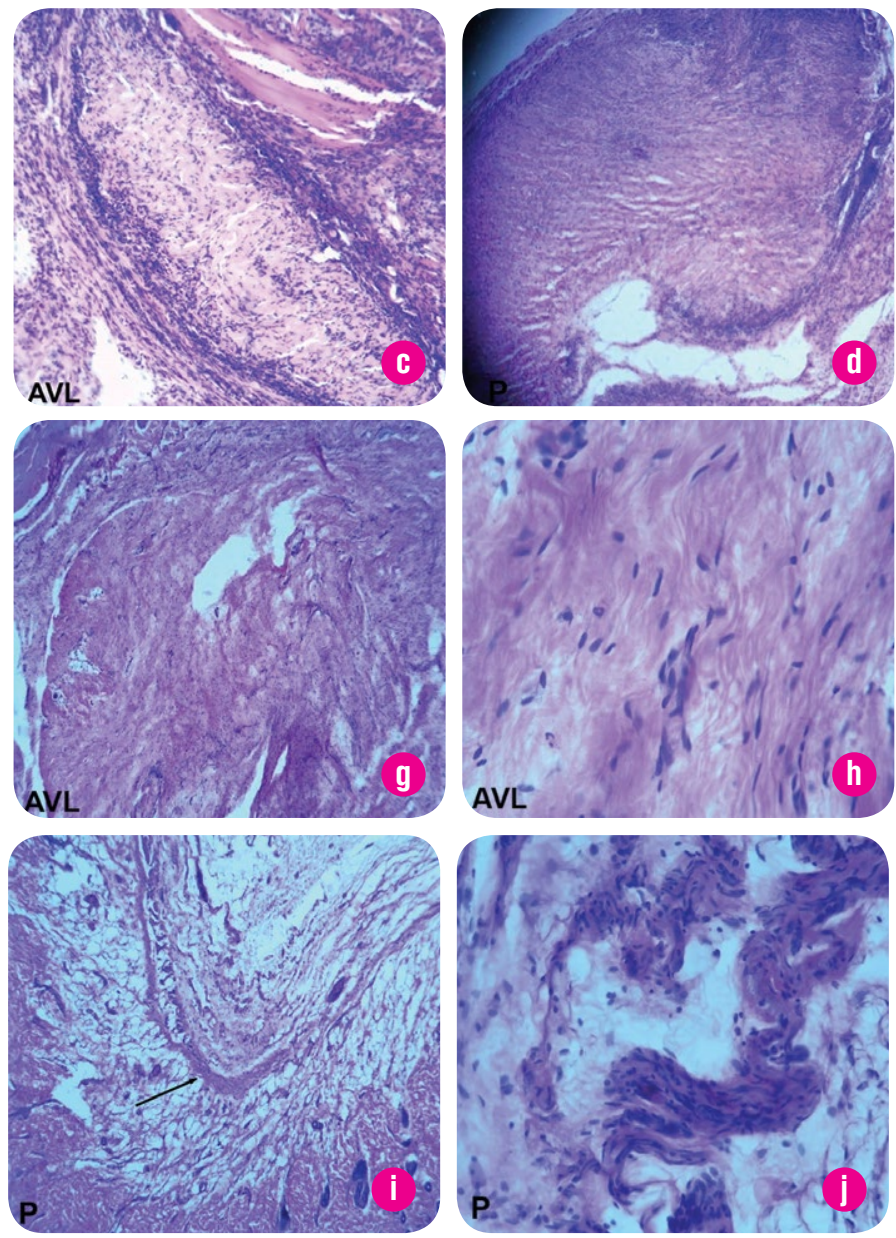

Fig. 6. Photomicrographs of aortic valve leaflets (AVL), pericardium (P) and the morphology of surrounding tissues after implantation. Group FR (tissue after freezing-thawing and subsequent irradiation at a dose of $25 \mathrm{kGy}$ ). Hematoxylin and eosin staining. a) after 14 days: the implant is solid and surrounded by a bilayer capsule;

oc. $x 4$, ob. $x 10$;

b) 14 days after: invasion of capillaries and fibroblasts from the surrounding tissue; oc. $\times 25$, ob. x10;

c) after 1 month: large fragment with a capsule of fibrous connective tissue and lymphocytes; oc. x10, ob. x10;

d) after 1 month: compact implant is surrounded by a thin capsule of

fibrous tissue, clusters of macrophages and lymphoid cells; oc. x4, ob. x10; e) after 3 months: fibrous structure, low cellularity, an abundance of capillaries (arrows) in the center of implant; oc. x25, ob. x10;

f) after 3 months : the implant surrounded with a thin capsule of fibrous tissue, low cellularity of the implant and surrounding tissue; oc. $\times 4,0 b . \times 10$; g) after 6 months: a massive solid transplant, intact surrounding tissues;

oc. $x 4$, ob. $x 10$;

h) after 6 months: implant fragment, visible fibers, fibroblast nuclei, microvessels; oc. $\times 40$, ob. x10;

i) after 12 months: a continuous strand of the implant; oc. $x 4$, ob. x10 j) after 12 months: small fragments of implant infiltrated by lymphocytes; oc. $\times 20$, ob. $\times 10$

phages and clusters of small lymphoid cells (Fig. 6, e). In the surrounding tissues, there was no inflammation but there was its typical structure with pigmented macrophages (Fig. 6, f). The leaflets had fragments with giant cells and pigmented macrophage invasion, i.e. focal resorption apparently continued there and the process of cellular elements residues resorption was completing. 
Table 1. Markers of engraftment and inflammation after subcutaneous implantation of porcine xenogeneic pericardium and aortic valve leaflets in different groups of rats in the dynamics

\begin{tabular}{|c|c|c|c|c|c|c|c|c|c|}
\hline \multirow{3}{*}{ 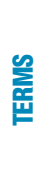 } & \multirow{3}{*}{ 象 } & \multicolumn{4}{|c|}{ INFLAMMATION } & \multirow{2}{*}{\multicolumn{2}{|c|}{$\begin{array}{l}\text { CAPSULE AND DEGREE } \\
\text { OF ITS MATURITY }\end{array}$}} & \multirow{2}{*}{\multicolumn{2}{|c|}{$\begin{array}{c}\text { COMPACTNESS } \\
\text { OF THE TRANSPLANT }\end{array}$}} \\
\hline & & \multicolumn{2}{|c|}{ IN SURROUNDING TISSUE } & \multicolumn{2}{|c|}{ IN IMPLANT } & & & & \\
\hline & & $\begin{array}{l}\text { PERICAR- } \\
\text { DIUM }\end{array}$ & AVL & $\begin{array}{l}\text { PERICAR- } \\
\text { DIUM }\end{array}$ & AVL & PERICARDIUM & AVL & $\begin{array}{l}\text { PERICAR- } \\
\text { DIUM }\end{array}$ & AVL \\
\hline \multirow{4}{*}{$\underset{0}{\frac{\pi}{0}}$} & $\mathrm{~N}$ & ++++ & +++ & +++ & +++ & thick GT & thick GT & C & C \\
\hline & $\mathrm{F}$ & ++++ & ++ & ++ & ++ & thick GT & moderately thick $\mathrm{GT}+\mathrm{F}$ & C & C \\
\hline & $\mathrm{R}$ & ++ & ++ & ++ & ++ & thick GT & moderately thick GT + LB, M & C & LF \\
\hline & $\mathrm{FR}$ & ++ & ++ & ++ & ++ & thick GT & moderately thick $G T+L, M$ & C & C \\
\hline \multirow{3}{*}{$\begin{array}{l}\vec{\pi} \\
\stackrel{0}{+}\end{array}$} & $\mathrm{N}$ & ++ & ++ & + & ++ & thick GT + L, M & thick GT & $\mathrm{Fr}$ & $\mathrm{Fr}$ \\
\hline & $\mathrm{F}$ & + & + & + & + & moderately thick $\mathrm{GT}+\mathrm{L}, \mathrm{M}$ & thin $\mathrm{GT}+\mathrm{F}$ & C & C \\
\hline & $\mathrm{FR}$ & + & + & + & + & moderately thick GT + FCT & thin, mature GT & C & C \\
\hline \multirow{4}{*}{$\begin{array}{l}\text { F } \\
\text { 들 } \\
\text { E }\end{array}$} & $\mathrm{N}$ & ++ & ++ & + & + & thick $G T+L$ and $F$ & moderately thick GT $+\mathrm{L}, \mathrm{M}$ & $\mathrm{Fr}$ & $\mathrm{Fr}$ \\
\hline & $\mathrm{F}$ & + & + & + & + & thin LCT & thin $\mathrm{GT}+\mathrm{L}$ & C & C \\
\hline & $\mathrm{R}$ & + & + & 0 & 0 & LCT & cell ring & LF & LF \\
\hline & FR & 0 & + & + & 0 & thin FCT & thin LCT, somewhere FCT & C & C \\
\hline \multirow{4}{*}{ 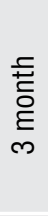 } & $\mathrm{N}$ & ++ & + & + & + & absent & thin $\mathrm{GT}+\mathrm{L}, \mathrm{M}$ & SF & SF \\
\hline & $\mathrm{F}$ & + & & + & & thin FCT & - & C & - \\
\hline & $\mathrm{R}$ & + & + & + & 0 & thin LCT & absent & C & LF \\
\hline & $\mathrm{FR}$ & 0 & + & + & 0 & very thin, FCT & thin FCT & C & C \\
\hline \multirow{3}{*}{$\begin{array}{l}\text { F } \\
\text { 들 } \\
\text { E } \\
0\end{array}$} & $N$ & 0 & 0 & + & 0 & absent & absent & SF & SF \\
\hline & $\mathrm{F}$ & 0 & 0 & + & 0 & thin FCT & absent & LF & SF \\
\hline & $\mathrm{FR}$ & 0 & 0 & 0 & 0 & very thin FCT from the side of MT & very thin FCT from the side of MT & C & C \\
\hline
\end{tabular}

Notes:

Groups: $N$ - native tissues; $R$ - tissues irradiated at a dose of $25 \mathrm{kGy} ; \mathrm{F}$ - tissues after freezing $\left(-196^{\circ} \mathrm{C}\right)$ and thawing; $F R$ - tissue after freezing and thawing, and subsequent irradiation at a dose of $25 \mathrm{kGy}$.

Histological description: AVL - aortic valve leaflets; GT - granulation tissue; LCT - loose connective tissue; GT - granulation tissue; FCT - fibrous connective tissue; MT - muscular tissue; L - lymphocytes; M - macrophages; F- fibroblasts; LB - lymphoblasts; Fr - fragmented; SF-small fragments; LF-large fragments; C - compact. Scale: 0 - no evidence; (+) - single cells (neutrophils, Iymphocytes, macrophages, eosinophils); (++) - small foci; (+++) - separate and drain foci; (++++) - extensive infiltrates.

At 6 months after surgery, the devitalized tissues were only a massive integral structure, in which a continuous progress of spirals could be traced. Between the fibers, there were numerous fibroblast nuclei and full-blooded microvessels, ingrowing from the adipose tissue islands. This may indicate an active process of repopulation, promoting tissue repair. There were individual short sections of the thin capsule on the side of the muscle layer and a good integration of the transplant into the surrounding tissue without signs of resorption and inflammation (Fig. 6, g, h). However, there were samples with partial edge destruction showing a local character.

After 12 months, the pericardium retained its structural integrity, it was a thin continuous strand surrounded by connective tissue with no signs of inflammation. We observed compact fiber bundles with corrugated structure. An insignificant edge macrophage activity remained, being indicative of rather slow edge biodegradation. At this stage, there was no visible capsule, the graft was fully integrated into the recipient tissue (Fig. 6, i, j). Thus, the implantation results demonstrate different dynamics of xenogeneic engraftment of the tissues being subjected to different types of treatment (Table 1).

In the case of native sample implantations, inflammatory reaction in the surrounding tissue and directly in the areas of implant contact was represented until the $3^{\text {rd }}$ month; lymphocytes and macrophages came to replace the neutrophils only between the $14^{\text {th }}$ and $30^{\text {th }}$ days.
The transplants were subjected to active resorption; there occurred edema, unfolding, nuclei dislocation and sequestration. As a result, relatively large transplant fragments were seen by the $2{ }^{\text {nd }}$ week and only small ones by the $3^{\text {rd }}$ month.

Thus, there occurred a replacement of the main implant mass with a regenerate, having a structure similar to the subcutaneous fat. Formation of connective tissue capsule did not occur: up to the $1^{\text {st }}$ month, granulation tissue surrounded the fragments, and by $3^{\text {rd }}$ month and later no signs of a shaft or a capsule were seen.

Compared to the native tissue samples, the inflammatory processes in animals with cryogenic treated tissue were expressed not so strongly and reduce faster, being manifested only by moderate leukocytes infiltration at the early stages of our observation. Up until the $3^{\text {rd }}$ month, the implants presented rather a compact structure and maintained their integrity in the surrounding of a thin LCT capsule. The transplant lysis was slow with simultaneous intergrowth of autologous cells and vessels. After 6 months, the graft was divided into fragments of different sizes intermittent with areas of unaltered adipose tissue.

Histological changes observed in the implantation zone of samples after ionizing radiation treatment are generally similar to the freezethawing group, except indistinct reaction of recipient's tissues. By the 1 st month after transplantation, inflammatory reaction of the surrounding 
tissues decreased or disappeared completely, only some areas had an accumulation of pigmented macrophages with single lymphocytes. There was a disorder of the transplant compactness and integrity represented by large unfolded fragments of its connective tissue bundles. After a longer period following implantation the connective tissue capsule around transplant fragments was not determined, but unfolding and fragmentation of implants continued. The macrophages performed gradual lysis of the implants.

The intensity of inflammatory response to implants after devitalizing treatment (group FR) decreased in the tissues of the recipient bed, even at the early stages (day 7 ). Since 14 days, such tissue reaction with a less pronounced inflammatory phase resulted in a rapid formation and maturation of the connective tissue capsule. This period revealed the first signs of fibrous capsule formation. After 1 month it was well pronounced and remained the same in 3 and 6 months. As a result, a relatively weak and soon reduced inflammatory reaction in the surrounding tissue, a quick change of polymorphonuclear cell population to the lymphocytes and macrophages (up to 14 days), active angiogenesis and a rapid formation of mature connective tissue capsule led to quick implant sprouting with recipient tissue with a thin capsule. By 6 months, the main part of biomaterial remained compact and retained the characteristic structure with multiple fibroblasts and microvessels. In 12 months after implanting the devitalized tissues still maintained their structural integrity and were surrounded by connective tissue without inflammation. There was compactness of bundles with the corrugated fibers, minor macrophage activity and full integration of the transplant into the recipient tissues.

\section{CONCLUSION}

Morphological analysis of the pericardium and aortic valve leaflets after different types of treatment and xenotransplantation revealed fundamental differences in indicators of engraftment and tissue response for specimens subjected to low temperature and $\beta$-radiation combined treatment compared with only cryopreserved or irradiated implants tissue.

Cryoradiation treatment of the pericardium and aortic valve leaflets greatly reduces the immune response to the implantation: rapid and intense formation of mature connective tissue capsule succeeds weak inflammation; active angiogenesis results in rapid intergrowth and good integration into the recipient tissue. Thus, we can assume that devitalized tissues stimulate an early repair of the recipient tissues. Devitalized implants at all stages of observation preserve compactness and structural integrity, marginal biodegradation is slow. After 12 months, the border between the implant and connective tissue erased - biomaterial fully ingrown recipient's tissue, indicating biointegration of own connective tissue in the implant, followed by its replacement. That is a remodeling sign and a proof of its low immunogenicity.

Our study confirms the possibility of using xenogeneic pericardium and aortic valve leaflets treated by cryoradiation methods to restore structural integrity of soft tissue.

\section{REFERENCES}

1. Goltsev AM, Gordienko EA, Babiychuk GO, et al. Aktual'nye problemy kriobiologii i kriomeditsiny [Actual Problems of Cryobiology and Cryomedicine]. Kharkov: Rider, 2012. $767 \mathrm{p}$ [in Russian].

2. Byzov DV. Primenenie nizkikh temperatur dlya sozdaniya devitalizirovannykh sosudistykh skaffoldov [The use of low temperatures for creation of devitalized vascular scaffolds]. Kharkov, 2012. $146 \mathrm{p}$ [in Russian].

3. Byzov DV, Synchikova OP, Pushkova EN, et al. Biotekhnologicheskie aspekty sozdaniya transplantatov arteriy [Biotechnological aspects for creation of arteries transplants]. Biotekhnologiya - Biotechnology. 2010; 3(3): 21-30 [in Russian]

4. Sandomirsky BP, Byzov DV, Mikhailova IP, Synchikova OP, et al., inventors. Sposib pidgotovki ksenogennikh arteriy dlya sudinnogo protezuvannya [Way to prepare xenogenic arteries for vascular prosthesis]. Patent of Ukraine \# 68379 IPC A61L27/00, A01N1/02. 2012 March 26 [in Ukranian].

5. Mikhailova I, Sandomirsky B, Gorlenko A. Effect of low temperatures and ionizing irradiation upon physical-mechanical properties and connective - tissue structures of porcine fibrous pericardium and aortic volve leaflets. Period Biolog. 2014; 116(1): 105-114.

6. Mikhailova IP, Manchenko AA, Byzov DV. Fiziko-mekhanicheskie svoystva devitalizirovannykh ksenoimplantatov na osnove perikarda, stvorok aortal'nogo klapana i arteriy [Physical and Mechanical Properties of Devitalized Xenografts Based on Pericardium, Aortic Valve Leaflets and Arteries]. Problemy kriobioloii i kriomeditsiny Probl. Cryobiol. Cryomed. 2015; 25(4): 311-328 [in Russian].

7. Repin NV Marchenko LN, Govorukha TP., et al. Ul'trastruktura tkaney perikarda i stvorok aortal'nogo klapana svin'i, devitalizirovannykh krio- i radiatsionnym vozdeystviem [Ultrastructure of Porcine Pericardium and Aortic Valve Tissues, Devitalized with Cryogenic and Irradiation Exposures]. Problemy kriobioloii i kriomeditsiny - Probl. Cryobiol. Cryomed. 2015; 25(3): 246-54 [in Russian].

8. Sevastyanova VI, Kirpichikova MT. Biosovmestimye materialy [Biocompatible materials]. Moscow: MIA, 2011. $511 \mathrm{p}$ [in Russian]

9. Danilov RK, Klishov AA, Borovaya TG. Gistologiya cheloveka v mul'timedia [Human Histology in multimedia]. SP.: ELBI - SPB, 2003. 362 p. Cp.: ELBI - SPB., 2003 [in Russian].

10. Serov VV, Schechter AB. Soedinitel'naya tkan' [Connective Tissue]. Moscow: Medicina, 1981. $312 \mathrm{p}$ [in Russian].

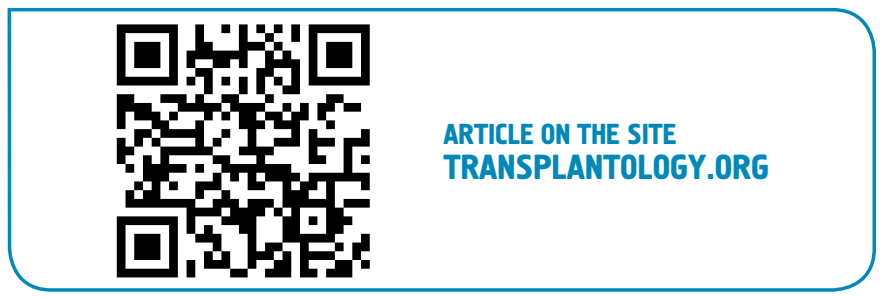

